\title{
Examining the association between dust and sediment and evaluating the impact of climate change on dust and providing adaptation
}

\author{
Safieh Javadinejad $^{1^{*}} \quad$ Rebwar Dara $^{1} \quad$ Forough Jafary $^{1}$
}

\begin{abstract}
In this research, the catchment area of the Karkheh River has been investigated in order to investigate the relationship between the sediment and the effect of climate change on the phenomenon of microstrip. In the first step, to determine the relationship between the grains and sediments, it is necessary to determine the origin of sedimentation and its gradation. Accordingly, some sediment samples were taken from the river bed. Sediment aggregate size measurement is an important tool for studying its origin. Currently, for statistical purposes, many samples are used, but these methods are time-consuming and difficult. The size of the sediment in the study of origin, and its relationship with the micro-organisms, is an important factor. Therefore, the use of modern methods is essential. In the present study, the data of the sediment samples were introduced into the acetate gradient (statistical analysis program) to determine the texture and granulation of the sediment. The results showed that sand gravel texture is. Then sampling and testing on the microscopes showed that they are also of sandy origin, so it can be assumed that abrupt grafting of microspheres after sediment can cause sediment in the river. In addition, in order to investigate the effect of climate change on the micrographs, the relationship between three climatic parameters including rainfall, minima and relative humidity with the number of days with a rigorous refreshment for two years of 2015 and 2016 were analyzed. The results showed that, with increasing temperature and decreasing precipitation and relative humidity, the number of days with the coarse cutter increases, and as a result, it can be caused by sedimentation as part of sedimentation in the river.
\end{abstract}

Keywords: sediment, seed size, Karkheh catchment basin, Rizgar, climate change

\section{Introduction}

Today, with the destruction of forests, the expansion of cities and the construction of highways, soil erosion, sedimentation and sedimentology have received much attention from experts ${ }^{[1-3]}$. Especially in the catchment area that has water structures or the construction plan of these structures is considered and also the basin faces many problems in terms of water quality, it is necessary before any action, whether in terms of construction of a new or optimal structure using the previous structures, and exploiting the water of the basin, detailed studies in terms of sedimentology and investigating the origin of their creation should be done to build a new structure or a decision to exploit river water with more confidence ${ }^{[4-6]}$. Due to

Received: Sept. 30, 2020 Accepted: Nov. 11, 2020 Published: Nov. 16, 2020

* Correspondence to: Safieh Javadinejad, Department of Water Engineering, University of Birmingham, Edgbaston St, Birmingham, B152TT, UK; Email: javadinejad.saf @ut.ac.ir ${ }^{1}$ Department of Water Resource Engineering, University of Birmingham, Edgbaston St., B152TT, UK

Citation: Javadinejad S, Dara R and Jafary F. Examining the association between dust and sediment and evaluating the impact of climate change on dust and providing adaptation. Resour Environ Inf Eng, 2020, 2(1): 61-70.

Copyright: $\odot 2020$ Safieh Javadinejad, et al. This is an open access article distributed under the terms of the Creative Commons Attribution License, which permits unrestricted use, distribution, and reproduction in any medium, provided the original author and source are credited. the fact that Karkheh River supplies drinking water, agriculture and part of electricity and has various hydraulic structures, the study of sedimentology, hydrology and sediment production in this basin is of particular importance, so more detailed studies and more intensive work should be done in all related fields, especially sedimentological issues ${ }^{[7-9]}$. Especially considering the problem of climate change and also the existence of severe dust in the Karkheh area and the involvement of these cases in the formation of sediments in the riverbed and the possible pollution of river water, so the study of sedimentology is very necessary ${ }^{[10]}$. The internal and external studies that have been done so far have been solely on the size of river sediments or only on sediment pollution. For example ${ }^{[11]}$, they dealt with the physical properties and granulation-sediments of the Sarbaz River in southern Iran. Also ${ }^{[12]}$ have studied the chemical properties of sediments for Jajroud River and reuse of sediments for agricultural operations ${ }^{[13]}$. Investigated the concentration of heavy elements in the sediments of the Karun River. Therefore, so still, no comprehensive study has been conducted in Iran to study the origin of sediments according to their physical characteristics and considering the contribution of dust and climate change (in areas facing this 
problem) on river sediments. Karkheh River is one of the important arteries of Khuzestan province. It receives a large amount of sediment annually, which has caused major problems in the operation of this river. Due to the high volume of sediment in this river and the potential for pollution, it is necessary to study the origin of sediments according to their size. Also, because this watershed is facing the repetition of the phenomenon of dust storm, the role of dust on the amount of sediment has been studied in this study and also due to the impact of climate change, which has been abundant in recent years, the role of the effect has also been investigated on the generation of dust and sediment.

\section{Materials and methodology}

The structure of the methodology of this study based on:

1)Analyze the resource of the dust in the study area by size of the dust (collecting samples)

2) Assess the impact of climate change parameters (like precipitation, minimum temperature and humidity) on dust and estimate the trend of these impacts by using regression model

3) Validate the model by using t-statistical test

\subsection{Geographical location and characteris- tics of the study area}

Karkheh watershed is located between 33-25 to 34-56 north latitude and 46-7 to 49-11 east longitude. Figure 1 shows the location of Karkheh watershed. This basin is limited to Sefidrud and Markazi watersheds from the north and to the border watersheds from the west to Dez and Markazi watersheds from the east and to Karkheh Sofla from the south. The area of Karkheh basin covers 4262000 hectares and covers parts of Khuzestan, Ilam, Hamedan, Lorestan, Markazi, Kurdistan and Kermanshah provinces. The most important tributaries of Karkheh River are: Gamasiab, Qarasu, Seymareh and Kashkan, which are divided into four sub-basins by the name of these four rivers ${ }^{[14]}$.

Seymareh sub-basin with an area of 15735 square kilometers with an average slope of 26.68 percent, Gamasiab sub-basin with an area of 11,690 square kilometers with an average slope of 19.53 percent, Kashkan sub-basin with an area of 9560 square kilometers with a slope of 26.1 percent, Qarasu sub-basin with an area of 5635 square kilometers with an average slope of $16.14 \%$.The whole Karkheh river with a length of $660 \mathrm{~km}$ has a gross slope of $32 \%$ and a net slope of $25 \%$ with an average weight of $32 \%{ }^{[15]}$. This basin is in a mountainous region with an average slope of $22.6 \%$ and is similar to the Zagros basin in terms of climate, so that in the southernmost point of the basin with an average rainfall of $300 \mathrm{~mm}$ and in the northern parts of the basin with $1000 \mathrm{~mm}$ per year. The average flow of the Karkheh River is 200 cubic meters per second and the flow of the river is about 12 billion cubic meters per year. The average rate of soil erosion in the basin is 16 tons per hectare per year, which unfortunately at the level of 430 thousand hectares of soil erosion in the basin is about 26 tons per hectare per year, which is one of the critical areas in terms of planning and prioritization and the first priority is the work of the designated field ${ }^{[16,17]}$.

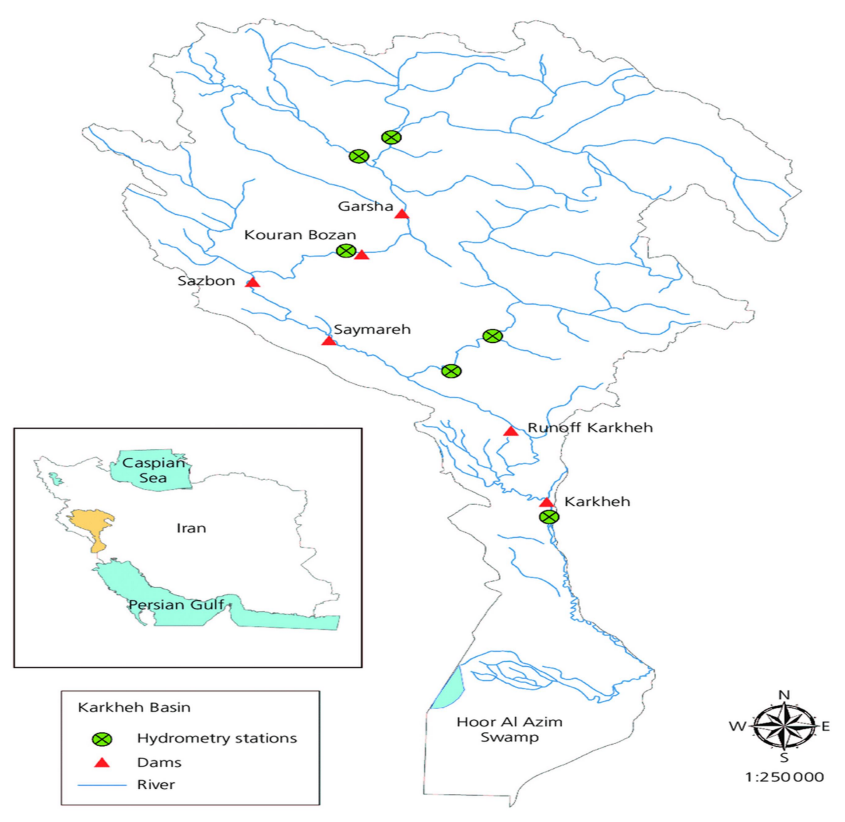

Figure 1. Location of Karkheh catchment area (Khuzestan regional water ${ }^{[18]}$ )

\subsubsection{Climate and meteorological conditions}

In Karkheh watershed, the main source of rainfall in the basin is the wet currents of the Sudanese Mediterranean (Persian Gulf and Red Sea) and the North Atlantic. The average rainfall of the basin varies from $300 \mathrm{~mm}$ in the southern regions and more than $1000 \mathrm{~mm}$ in the northern and northeastern heights ${ }^{[?]}$.

In general, Karkheh basin is affected by three types of wind:

The first wind is the cold current of mountainous areas that moves towards the Persian Gulf in winter and brings colder air in this season. 2- Coastal winds that blow from the Persian Gulf from time to time in summer and carry a lot of moisture with them to warm plains, which are also called sultry winds. 3- The most unfavorable situations are created by the wind that blows from Saudi Arabia. This wind, known as toxins, always carries some soil and sand. In addition, this wind stores a lot of moisture when 
crossing the Persian Gulf. Toxic wind is one of the main causes of dust in the region ${ }^{[20]}$.

\subsubsection{Dust situation and related factors}

The most important dust hotspots and susceptible areas as mentioned before, due to the underlying land of Khuzestan plain and its coverage by alluvial sediments of the fourth period, many of its areas are either hotspots or exposed to becoming the area with the focus of dust ${ }^{[21,22]}$.

\subsubsection{Abadan Delta}

The Abadan Delta is one of the most important centers of dust, which is completely covered by the sediments of Karkheh, Karun and Arvand rivers. Extreme temperatures, as well as recent droughts, have put the region at greater risk of wind erosion and increased dust hotspots.

Due to the low slope of the delta, the riverbed in this area is divided into several branches and is so-called aquifer movement. The texture of alluvium is mainly in the form of sand and mud particles and gradually we encounter coarser sediments. The high volume of alluvium has caused the delta base to advance several meters per year and has led to the rapid development of the delta. Hot winds from the deserts of Iraq and Saudi Arabia have activated erosive currents in the region; So that many forms of geomorphology of desert areas are observed in this area. The presence of fine-grained sediments and the availability of wind erosion conditions have made this region one of the poles of dust generation in the region.

\subsubsection{Sand dunes and sand fields}

One of the main and influential centers on the dust process in the region is the sand dunes and abundant sand fields that are located in the northwest and southeast of this region. These hills and sand dunes cause sandstorms every year due to the monsoon winds. The geological formations of the basin include protrusions of the Aghajari Formation and alluvial sediments related to the fourth geological period. The maximum altitude is 76.7 meters in the region and the average altitude is 16.1 meters and the maximum slope is 0.6 percent. The conditions of wind erosion and the creation of dust hotspots in this region, especially its northwest and southeast, are quite suitable and abundant.

The most important causes of dust and wind erosion

\section{(1) Alluvial and flood sediments:}

As mentioned, Karkheh Basin is covered with young alluvial sediments brought to this area by the Zagros rivers, especially in the Quaternary. It goes without saying that during the Quaternary glacial phases, river erosion was much higher than it is today due to the regression of the Persian Gulf as well as climate change that led to wetting and semi-wetting of the region. On the other hand, rivers in Khuzestan plain are divided into many branches due to its very gentle slope and due to this slope, they leave a large volume of sediments in this area. These rivers change their bed or beds in a short time and the previous bed of the river is dry and thus, with abundant alluvial sediments, it is prone to wind erosion ${ }^{[23]}$.

(2) The absence of wind erosion centers from vegetation and desertification growth:

One of the main causes of wind erosion is the so-called bare ground. Since our study area is covered with alluvial and quaternary sedimentary sediments and is added to these sediments every year, and due to the heat and dryness of the area and the area free of vegetation, the conditions for wind erosion are ready. The lack of vegetation in the area provides a good ground for desertification. In addition, factors such as the establishment of subtropical high-pressure cells, deforestation, lack of ascent and intense air movement, hot winds and low thermal pressure, cause several droughts in the region that contribute to desert development in the region. ${ }^{[24-26]}$.

\section{(3) Anthropic erosion:}

In the last century, human mismanagement has always been one of the main causes of environmental change. This is also very true in the issue we are discussing. As we know, natural changes usually become apparent little by little, but this obvious change can by no means be natural, and traces of human erosion must also be sought in it. Development of oil drilling and extraction, regardless of environmental conditions, diversion of rivers and encroachment on their territory, overgrazing, cutting down trees for fuel use, land conversion rangeland to agricultural lands, drainage of their water and such issues are the most important factors and manifestations of entropic erosion in the region. According to the way deserts and deserts were formed, it is clear that human did not have a direct involvement in their formation, but unknowingly and with the action that human acts, causes the expansion of deserts. Many desert areas of the region have also increased in recent years due to human activities and problems cause them to be guided, which is one of the most important of them. There is dust in this area, of course, with proper planning and principles that prevented these problems.

Overview of the internal factors of dust compared to external factors the interior should not be ignored either. It is clear that a large part of the existing dust is of foreign origin and reaches Iran mainly from the Sahara desert, especially Iraq and Syria, but if the local dust currents do not amplify them, they will never reach such inten$\operatorname{sity}^{[20,27,28]}$.

\subsubsection{Floods}

The effective factors that have been studied on floods in this area are the time of snowfall, the depth of accumulated snow, the slope of the basin, the shape of the basin, 
soil type and vegetation, respectively. Therefore, in some dry seasons of the year, the flow of Karkheh River at the entrance of the dam reaches less than 18 cubic meters per second and in flood seasons reaches more than 5100 cubic meters per second ${ }^{[29-31]}$.

\subsubsection{Sediment status}

To study sedimentology, samples were taken from different sections along the river and after preparing granulometric studies and particle size analysis, the results were as follows. The purpose of sampling is to study the type of river sediments. About $60 \%$ of the total suspended load is estimated during November, December, April, May and June, and the main reason is that November and December generally coincide with seasonal rainfall and April and May coincide with rainfall and snowmelt. It is from the level of the constituency. Also, in the same months, autumn and spring cultivation operations are carried out on agricultural lands. In total, about $99.5 \%$ of the suspended load of the river during the months of November to the end of June and only less than $0.5 \%$ (about 0.1 million tons) in the months of July to late October has crossed the river. Estimated values and the obtained trend show that the suspended load in January compared to the month before and after shows a decrease that can be due to frost and snow cover in most parts of the basin.

\subsection{Methodology for dust analysis and associ- ation with climate change}

\subsubsection{Basic granulation analysis}

Determining the best grain size distribution of different sediments is often described using the standard deviation criterion. They are seldom used by sedimentologists, so much emphasis has been placed on coarse and finegrained sediments. Geometric scales are usually used with similar emphasis on small differences in fine particles and large differences in large particles. Most sedimentologists have adopted the Odontworth logarithmic grading scale, in which the boundary between two consecutive classes is different from two factors. In order to facilitate the presentation and statistical fitting of granulation frequency data, Cormbin (1974) suggested that the gradient boundaries should be converted to a logarithmic scale with values of $\Phi^{[32]}$.

$$
\varphi=\log _{2}^{d}
$$

Where $\Phi$ is grading scale and $\mathrm{d}$ is the size of the grain diameter in millimeters.

The distribution used in this scale is 2 normal logs and is commonly used by sedimentologists. Parameters used to describe the distribution of granulation into four main groups: (1) average size, mean, (2) size scatter around mean, sorting, (3) a criterion for the presence or absence of symmetry of the distribution function, skewness, and (4) A measure of the sharpness of a curve at the maximum point (elongation) is divided. These parameters can be easily obtained using mathematical or graphical methods. Among these, the mathematical method of torque is more accurate in the number of samples that can use.

Calculating the granulation parameters using the torque method has been a difficult process. However, approximations of the parameters can be obtained by obtaining information from plotting the data frequency either using the cumulative frequency curve, or by extracting or determining the input values for the whole curve using formulas. Is obtained. The formula proposed by Falak and Ward (1957) is widely used for calculations and its classification is shown in Table $1^{[33]}$.

Table 1. Sediment size classification (Falak and Ward, 1957)

\begin{tabular}{lll}
\hline Type & Unit $(\varphi)$ & Wentworth (mm) \\
\hline (boulder) Very big stone & $>-8$ & $>256$ \\
(cobble) Big stone & -6 to -8 & 64 to 256 \\
( pebble) & -2 to -6 & 4 to 64 \\
grain & -1 to -2 & 2 to 4 \\
Very large & 0 to -1 & 1 to 2 \\
large & 1 to 0 & 0.5 to 1 \\
Medium & 2 to 1 & 0.25 to 0.5 \\
Small & 3 to 2 & 0.125 to 0.25 \\
Very small & 4 to 3 & 0.0625 to 0.125 \\
Large & 5 to 4 & 0.0312 to 0.0625 \\
Medium & 6 to 5 & 0.0156 to 0.0312 \\
Small & 7 to6 & 0.0078 to 0.0156 \\
Very small & 8 to 7 & 0.0039 to 0.0078 \\
large & 9 to 8 & 0.00195 to 0.0039 \\
medium & 10 to 9 & 0.00098 to 0.00195 \\
\hline
\end{tabular}

Such appropriate methods are used to analyze the infinite distribution, then the parts of the distribution, which include the outliers, are ignored. With the development of computer data analytics in recent decades, the calculation of both torque methods and graph parameters can be done automatically, and some of the main advantages of other graph methods are no longer applicable ${ }^{[34]}$.

\subsubsection{Grid state program}

With the extensive needs of researchers in research such as geology and sedimentology, the grade acetate program has been written. This program (about 20 samples per hour) performs statistical calculation of granulation using two methods of Falak and Ward (1923) and torques quickly ${ }^{[32]}$, while the program is capable for analyzing the distributed grain data in the past ${ }^{[35]}$.

These calculations are often difficult and tedious. The program is written in Visual Basic, which connects to an integrated Excel spreadsheet and presents the output in both tabular and graphical formats. The user is required to enter the input in the program as a percentage. This can be done by using the residual weight in each sieve, or the percentage of sediment in any amount of residue, 
which can be used by granulometer, X-ray sediment or coil counters.

Computable statistical samples are mean 2, mode 7 , standard deviation 4, skewness 2, elongation 5 and a range of values in terms of cumulative percentage (granulation in a certain percentage of coarse grains), called D10, D50, D90, D90 / D10, D90 -D10, D75 / D25, D75 -D25. Based on weight of each sediment sample, weight, experimental amount and particle diameter measurement, the parameter of D can obtain (for more details please see the research by Falak and Ward (1923). In this program, a method of torques for statistical calculations such as the arithmetic method (based on a normal distribution with values in metric units) (geometric method) based on the normal distribution with values in metric (and logarithmic units) is based on a normal distribution with values in $\Phi$ ('s terms and formulas proposed by Cormbin and Patijan (1938). Linear interpolation is obtained between adjacent points specified in a curve, these points are used to calculate the parameters of the sky and the logarithm and the logarithmic parameters. The initial proposal in the sky and the $\log$ (1923), based on the normal distribution with $\Phi$ values (and geometrically) is based on the normal distribution with metric values. The formulas used in the calculations are shown in Table $2^{[32]}$. Statistical parameters are also proportional to the descriptive components. For terms consistent with mud and the percentage of sand, sand is a fraction consisting of five very finely derived layers $(2 \mathrm{~mm})$ to very large $(54 \mathrm{~mm})$. A piece of rock larger than $54 \mathrm{~mm}$ by the boards are described. To avoid confusion as well as proper skewness, the scales are metric or $\Phi$, positive skewness with "good skewness" (indicates too good skewness), and negative skewness with "large skewness" (indicating sequence with a large particle), which can be identified. This program uses a classification of textures (such as clay, sand, sand (already provided by the $1924 \mathrm{sky}$ ) for a physical description. It also contains a table obtained for the percentage of the fall of any fraction size. In terms of output, this program provides a graph of grain size distribution and cumulative distribution of data in both micrometers and $\Phi$, and displays the sample size in a triangular diagram of pebbles, clay, and sand. The samples can be analyzed individually or up to 220 possible samples with all statistical analyzes are provided to the user.

\subsubsection{Data and comparison of different parameters and granulation methods}

The characteristics of data collection stations with appropriate distances of about 500 meters were considered and sampling was done on a monthly basis (specific time) for each station and then the average of them considered in this study.

\subsubsection{Method of obtaining sediment granulation}

Sieving method or mechanical method of determining the grain size Sediment granulation was performed by sieving method. In order to perform sediment granulation, the collected samples were transferred to the laboratory and dried by a dryer at $100{ }^{\circ} \mathrm{C}$, then 100 The grams were separated from each sediment sample by a digital scale and each sample was placed in an automatic vibrating device for 5 minutes to separate the particles based on their large diameter size by the sieves in the device.

Sieves used in screening practice according to the minimum and maximum sand with pore diameters of $1,0.25$, $0.15,0.053,0.663,0.9,0.125, \mathrm{~mm}$, which correspond to the sieve numbers $10,35,60,100,140,230,400$, respectively, have been selected that can separate sediment grains from sand to coarse, medium-grained sand. They can separate fine grains and silt and clay particles. The reason for selecting these sieves is the type of sand regime with different granulation of sediments, which consists of coarse-grained sands larger than one millimeter to silty materials and particles smaller than 0.053 millimeters. At the end of the sieving stage, the weight of sediment grains instead of the residue on each sieve and finally the total weight of the sample used by the scale was measured with an accuracy of $0.01 \mathrm{~g}$ and the weight percentage and cumulative percentage according to the following equations for zinc sediments. Each sieve was calculated:

(2) $* \mathrm{w}=(\mathrm{ws} / \mathrm{tw}) \times 100$

Where $\mathrm{w}$ is weight percentage and ws is sediment weight per sieve and tw is total sample weight.

(3) $* \mathrm{cp}=(\mathrm{ws}+\mathrm{wpp})$

Where $\mathrm{cp}$ is cumulative percentage and ws is weight percentage of each sieve and wpp is weight percentage of previous sieves.

Finally, the obtained data, which included the weight of each sediment sample, weight percentage, cumulative percentage and particle diameter size, were recorded in special tables.

The prepared tables were entered into Excel software environment to determine the normal distribution and cumulative distribution of parameters such as $50 \mathrm{D}$, average diameter $50 \%$ by weight of sediments of a sample and mean $\mathrm{M}$ using curves to extract the above numbers in the analysis and Analysis of sediment granulation distribution conditions is very efficient in terms of sorting rate and uniformity coefficient. Sedimentary parameters such as sorting, sharpening and tilting were also determined using normal and cumulative distribution curves as well as existing formulas. The obtained values were entered in the acetate grid program and the granulation and sediment texture were obtained. The results obtained for the texture at different depths using the Grid stat program are 
available in the appendix of the article.

\section{Results}

\subsection{Granulation and sediment texture}

The data obtained from the granulation including the weight of each sediment sample, weight percentage, cumulative percentage and particle diameter size are presented in Table 2.

Table 2. The data obtained from the granulation including the weight of each sediment sample, weight percentage, cumulative percentage and particle diameter size

\begin{tabular}{llllll}
\hline \multirow{2}{*}{ No sieve } & \multicolumn{5}{c}{ Depth } \\
\cline { 2 - 6 } & 0 meter & 5meter & 10meter & 15meter & 20meter \\
\hline 10 & 0 & 0 & 0 & 0 & 0 \\
35 & 0.19 & 0.052 & 0.169 & 0.13 & 0.06 \\
60 & 0.16 & 0.075 & 0.021 & 0.01 & 0.04 \\
100 & 0.59 & 0.53 & 0.2 & 0.28 & 0.59 \\
140 & 0.053 & 0.22 & 0.29 & 0.24 & 0.23 \\
230 & 0.003 & 0.09 & 0.21 & 0.17 & 0.07 \\
400 & 0.004 & 0.033 & 0.11 & 0.07 & 0.01 \\
\hline
\end{tabular}

\subsection{The role of fine dust in the formation of river sediment}

After obtaining the results of river sediment granulation, the results of particulate matter sampling, for testing, analysis and diagnosis of particulate matter for two months of October and November 2015 to the reference laboratory of wind erosion, mulch and fine dust Yazd University (Yazd University, 2015) ${ }^{[36]}$ was sent.

The results show that fine dust also has a sandy origin, so it can be assumed that the phenomenon of dust and wind erosion and the transfer of dust particles to the south of the catchment can be effective in creating sand deposits in the river. The results of correlation (direct correlation) between samples of fine dust and river sediments were calculated using statistical analysis of correlation coefficient (SPSS) software. These results are presented in Table 3.

Also, according to the information obtained and maps of particulate matter frequency from the Iranian Space Agency (Iranian Space Agency, 2015) ${ }^{[37]}$, it can be concluded that the frequency of particulate matter (Figure 2 and 3) in October and November coincides with the frequency of sediment in this It is two months (Table 4). Figure 2 and 3 show the yellow and orange lines with the highest frequency of dust observed in the whole of Iran. As shown in the figure, in Karkheh basin, the most dust phenomenon occurred in October and November 2015.

As shown in Table 5, the highest amount of suspended load in 2015 for the Karkheh River belongs to the months of October and November, which may be because the

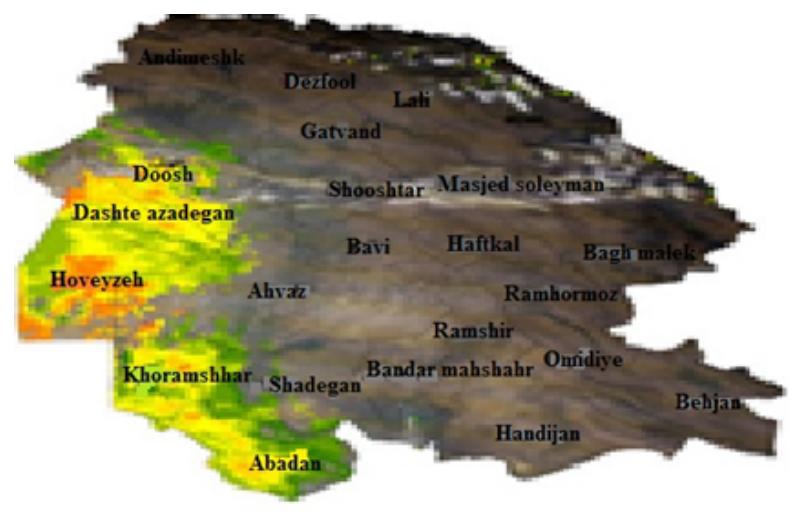

Figure 2. Map of fine dust phenomenon in October 2015

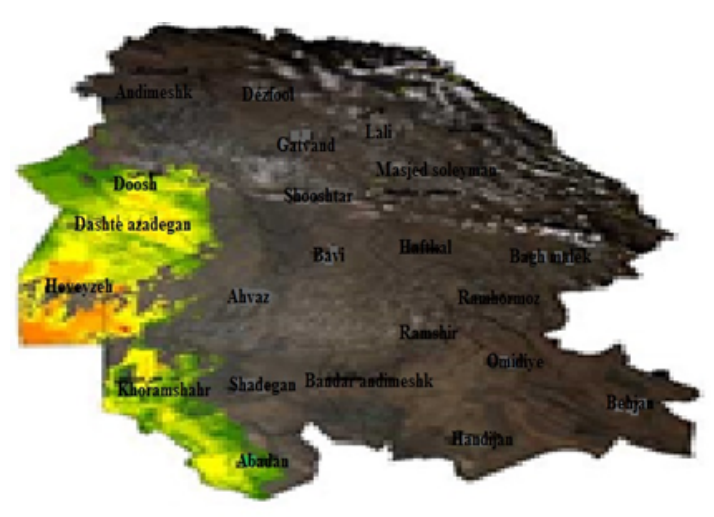

Figure 3. Map of fine dust phenomenon in November 2015

Table 3. Statistical analysis of correlation coefficient between samples of fine dust and river sediments

\begin{tabular}{cc}
\hline Number of sample & Correlation \\
\hline 1 & 0.7 \\
2 & 0.68 \\
3 & 0.80 \\
4 & 0.67 \\
5 & 0.85 \\
6 & 0.89 \\
7 & 0.74 \\
8 & 0.72 \\
9 & 0.76 \\
10 & 0.76 \\
11 & 0.83 \\
12 & 0.84 \\
13 & 0.77 \\
14 & 0.82 \\
15 & 0.86 \\
16 & 0.71 \\
17 & 0.79 \\
19 & 0.88 \\
20 & 0.85 \\
21 & 0.85 \\
22 & 0.69 \\
23 & 0.71 \\
24 & 0.66 \\
25 & 0.73 \\
26 & 0.80 \\
27 & 0.81 \\
28 & 0.69 \\
29 & 0.74 \\
30 & 0.77 \\
& 0.80 \\
\hline
\end{tabular}


Table 4. Monthly changes in suspended volumetric load and river concentration at Karkheh dam

\begin{tabular}{lccc}
\hline Month & Mean discharge & $\begin{array}{c}\text { Suspended load } \\
\text { (million tons) }\end{array}$ & $\begin{array}{c}\text { Medium concentration of } \\
\text { suspended solids }\end{array}$ \\
\hline Oct & 173 & $* 8.79$ & 9770 \\
Nov & 190 & $* 28$ & 3338 \\
Dec & 198 & 3.48 & 7720 \\
Jan & 240 & 2.3 & 5200 \\
Feb & 259 & 6.4 & 1106 \\
Mar & 266 & 7.9 & 1619 \\
Apr & 297 & 3.74 & 7932 \\
May & 289 & 6.74 & 8185 \\
\hline
\end{tabular}

months of October and November generally coincide with seasonal rainfall in the area of May Be. Also, in the same months, autumn planting operations are carried out on agricultural lands, and the phenomenon of dust storms is most frequent in these two months.

Figure 4 shows that the highest flow rate occurs in October to April of a blue year (2015) due to spring and autumn rains.

According to Figure 5, the highest amount of sediments is in November and December, which coincides with agricultural cultivation and the phenomenon of dust, according to Figure 2 and 3.

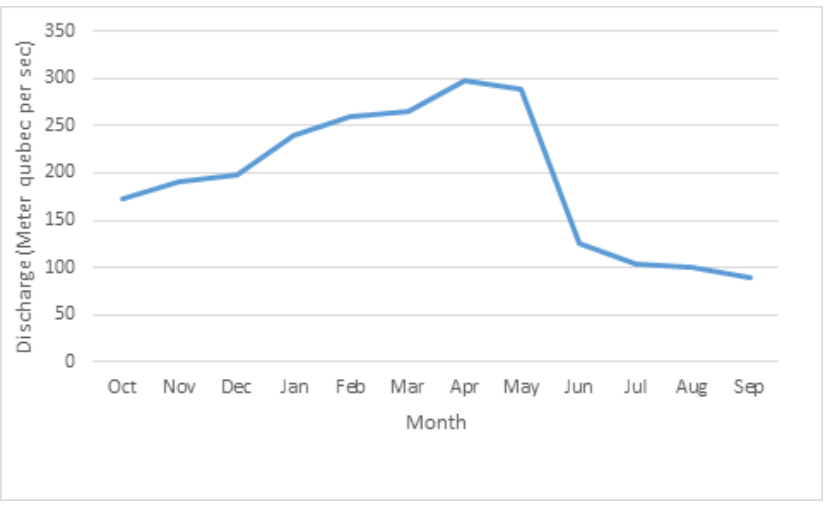

Figure 4. Mean river discharge

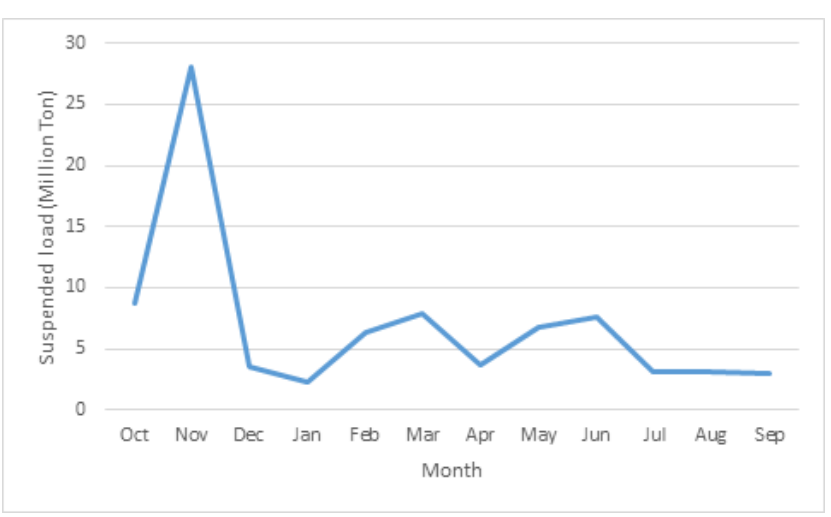

Figure 5. Sediment rate (suspended load)

\subsection{The role of climate change in the phe- nomenon of fine dust}

To investigate the role of climate change on the amount of fine dust, the relationship between 3 important climatic parameters including rainfall, relative humidity and minimum temperature with the number of days with dust for the two years 2015 and 2016 were analyzed and the results are shown in Figure 6, 7 and 8. Have been given. The results in Figure 6 show that the less rainfall, the more days with dust. Figure 7 and 8 show, respectively, that the lower the relative humidity and the higher the temperature, the greater the number of days with dust. In order to validate the relationship between dust and climate change parameters t-statistical test is used and the results are shown in Table 5. The table indicates there is high relation ship between dust and climate change parameters. Because the $\mathrm{p}$ values are less than 0.01 .

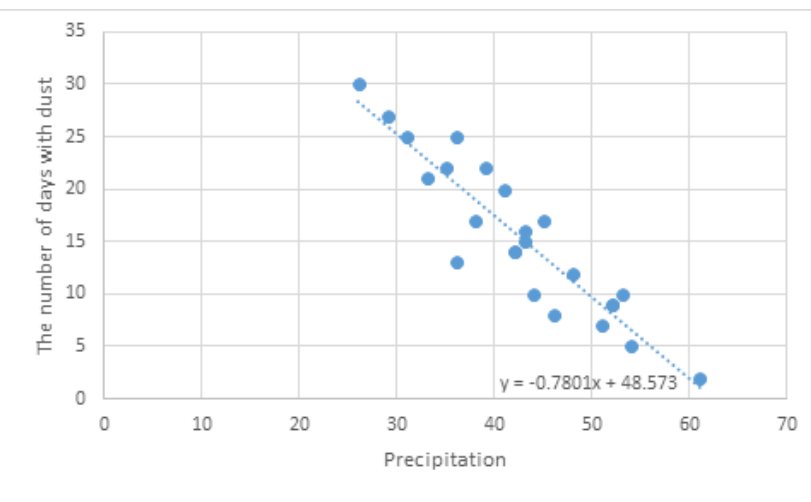

Figure 6. Changes in monthly rainfall with the number of days associated with heavy dust for the years 2015-2016

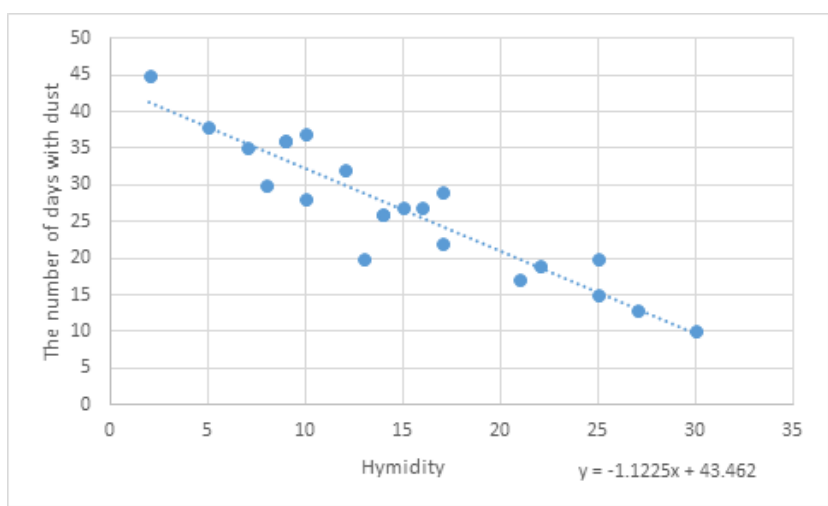

Figure 7. Changes in monthly relative humidity with the number of days associated with heavy dust for the years 2015-2016 


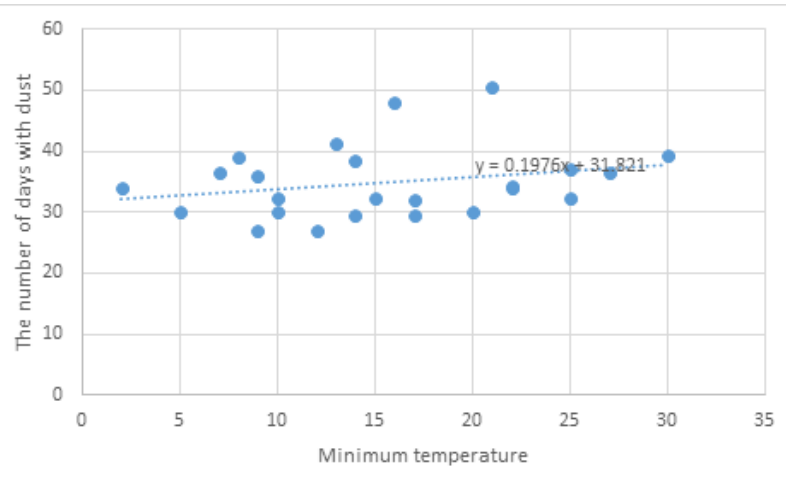

Figure 8. Changes in the minimum monthly temperature along with the number of days with severe dust for the years 2015-2016

Table 5. Relationship between climatic parameters and dust with using t-test

\begin{tabular}{lccc}
\hline Parameter & DF & t-statistic & Sig(p-value $)$ \\
\hline precipitation & 24 & 14.02 & $0.002^{* *}$ \\
humidity & 24 & 12.19 & $0.003^{* *}$ \\
minimum monthly temperature & 24 & 19.80 & $0.006^{* *}$ \\
\hline Note: $* * \mathrm{p}<0.01$ & & &
\end{tabular}

\subsection{Proposed solutions to deal with dust and its impact on river sediment}

To reduce the effect of climate change on the amount of sediment, actions can be taken to increase the amount of air humidity and thus reduce the amount of soil erosion, which is one of the factors that cause fine dust, and stabilize the soil. In the first solution, suitable vegetation can be used, even plants that consume low water, in order to increase the humidity of the air by photosynthesis. Another factor that prevents the formation of fine dust is the spraying of oil mulch to stabilize the quicksand, and as a result, the fine dust that can cause sediment in the river is reduced. Another solution is proper plowing of agricultural lands in the region. For example, the method of protective plowing (border plowing, slit plowing) causes the soil permeability to be more and the soil to be stabilized and less eroded, thus increasing soil moisture and less dust and reducing the effect of fine dust on river sediment. . Also, the creation of horizontal banquets along the alignment lines and the creation of protective platforms along the river causes more water to not penetrate to the ground and soil moisture to rise throughout the watershed, thus reducing both soil erosion and water erosion, and so less sediment is formed. According to the results of this study, there is a possibility of a significant relationship between the origin of sediment and the involvement of dust storm phenomenon in sediment formation in Karkheh river. In this study, according to the type and size of river sediment, its possible relationship with dust was realized.
Also, the existence of a significant relationship between increasing the minimum temperature and days with dust shows a close relationship between climate change and increasing storms. It has dust in the Middle East. If it does not control, we must be prepared to deal with more severe dust storms in the west and south of the country year after year.

\section{Discussion and conclusion}

The result of this study reached by the field work and we measured dust by collecting sampling in the river and analyze the source of these dust by analyzing the size of the dust grain and then by regression analysis and correlation coefficient we estimated the effects of the climate change parameters on the dust. We used SPSS t-statistical to analyze and confirm the effect of climate change on dust for validation test.

Although the change in the amount of wind in the region with dust also shows significant levels (which can also be a consequence of global warming), but the existence of higher levels of adaptation between dust and relative humidity and precipitation, along with temperature changes as the most important factor in creating dust in the region. It may be thought at first that rising temperatures increase evaporation and consequently increase relative humidity in the atmosphere, but what the results of this study show is that we are experiencing a decrease in relative humidity in this region, which it indicates that the area is drier. It is clear that dust is directly related to the amount of soil moisture, this can be clearly seen in the effect of months that had a significant trend in rainfall over the period of the study period on the amount of dust. It is possible that with the passage of time and the decrease of rainfall in spring, the amount of dust in this season has increased more sharply than other seasons.

However, regarding the reduction of relative humidity in the warm months of the year, it can be written that due to the fact that in the warm season, most of the agricultural lands in the region are barren and uncultivated, it has caused changes in humidity in different seasons. Clearly, this does not justify the drastic changes of the warm months in different years compared to the cold months, because if the changes in relative humidity were solely due to crop cultivation, the change in different years would have taken place at almost constant rates. So this issue must have another reason. What has been seen in recent years in the appearance of Karkheh Basin is the rapid change of land use in order to develop the city and the development of industrial centers in this area; the increase in the number of job-seeking immigrants to the city, in turn, exacerbates this. The impact of unsustainable de- 
velopment projects in the region, led by the construction of dams and the transfer of the basin to the water basin, as well as the over-harvesting of surface water from the surface water for the development of sugarcane cultivation projects and illegal irrigation of upstream agricultural lands, led to a decrease. Dubai River is Karkheh. On the other hand, in Iraq, which is adjacent to the Karkheh basin, due to the uncontrolled withdrawal of water by upstream countries, the Tigris and Euphrates rivers have become dehydrated and the associated wetlands have dried up. And dust have been identified in the area that can transport these dust particles to the Karkheh basin as well. On the other hand, pollution caused by industrial development in Karkheh region along with reduced water resources can cause more damage to vegetation. This is a positive feedback to increase the speed of desertification and reduce relative humidity and consequently increase dust and also increase river sediment. It can be noted that in the sediment phenomenon, not only dust but also the use of fertilizers Irregular agriculture during the growing season, which coincides with an increase in river discharge, contributes to the process of increasing river sedimentation. Obviously, solving these problems will have no solution other than achieving proper management in the light of sustainable development.

\section{References}

[1] Javadinejad S, Eslamian S, Askari OA. The Analysis of the Most Important Climatic Parameters Affecting Performance of Crop Variability in a Changing Climate, 2018.

[2] Javadinejad S, Eslamian S, Ostad-Ali-Askari K, et al. Embankments. In: Bobrowsky P., Marker B. (eds) Encyclopedia of Engineering Geology. Encyclopedia of Earth Sciences Series. Springer, Cham, 2018. https://doi.org/10.1007/978-3-319-12127-7_105-1

[3] Javadinejad S. The 2008 Morpeth Flood: Continuous Simulation Model for the Wansbeck Catchment. Ebook, Grin publication, 2011.

[4] Roddaz M, Viers J, Brusset S, et al. Boucayrand and G. Herail, Controls on weathering and provenance in the Amazonian foreland basin: Insights from major and trace element geochemistry of Neogene Amazonian sediments. Chemical Geology, 2006, 226: 31-65. https://doi.org/10.1016/j.chemgeo.2005.08.010

[5] Mirramazani SM, Javadinejad S, Eslamian S, et al. The Origin Of River Sediments. The Associated Dust And Climate Change.

[6] Mirramazani SM, Javadinejad S, Eslamian S, et al. A Feasibility Study of Urban Green Space Design in the Form of Smart Arid Landscaping with Rainwater Harvesting. American Journal of Engineering and Applied Sciences, 2019: 110.

[7] Abdollahi S, Javadinejad S, Ostad-Ali-Askari K, et al. Investigating the Effects of Landfill in Azad-Shahr City on the Physicochemical Properties of Groundwater. American
Journal of Engineering and Applied Sciences, 2019, 12(2): 136-146.

https://doi.org/10.3844/ajeassp.2019.136.146

[8] Baolin L, Yaping W, Xin S, et al. Elemental geochemistry of northern slope sediments from the South China Sea: Implications for provenance and source area weathering since Early Miocene. Chemie der Erde, 2013, 73: 61-74. https://doi.org/10.1016/j.chemer.2012.11.005

[9] Burg JP, Bernoulli D, Dolati A, et al. Stratigraphy and Structure of the Iranian Makran. International Conference and Exhibition, 2012.

[10] Tao H, Wang Q, Yang X, et al. Provenance and tectonic setting of Late Carboniferous clastic rocks in West Junggar, Xinjiang, China: A case from the Hala-alat Mountains. Journal of Asian Earth Sciences, 2013, 64: 210-222. https://doi.org/10.1016/j.jseaes.2012.12.019

[11] Li Y, Song Y, Kaskaoutis DG, et al. Atmospheric dust dynamics in southern Central Asia: Implications for buildup of Tajikistan loess sediments. Atmospheric Research, 2019, 229: $74-85$. https://doi.org/10.1016/j.atmosres.2019.06.013

[12] Arcusa SH, McKay NP, Routson CC, et al. Dust-drought interactions over the last 15,000 years: A network of lake sediment records from the San Juan Mountains, Colorado. The Holocene, 2020, 30(4): 559-574. https://doi.org/10.1177/0959683619875192

[13] Pérez-Martínez C, Rühland KM, Smol JP, et al. Long-term ecological changes in Mediterranean mountain lakes linked to recent climate change and Saharan dust deposition revealed by diatom analyses. Science of The Total Environment, 2020, 727: 138519.

https://doi.org/10.1016/j.scitotenv.2020.138519

[14] Middleton N. Variability and trends in dust storm frequency on decadal timescales: Climatic drivers and human impacts. Geosciences, 2019, 9(6): 261. https://doi.org/10.3390/geosciences9060261

[15] Javadinejad S and Jafary RDF. Effect of Precipitation Characteristics on Spatial and Temporal Varia-tions of Landslide in Kermanshah Province in Iran, 2020. https://doi.org/10.30564/jgr.v2i4.1818

[16] Javadinejad S, Dara R and Jafary F. Potential impact of climate change on temperature and humidity related human health effects during extreme condition. Safety in Extreme Environments, 2020, 1(1): 1-7.

[17] Javadinejad S, Dara R and Jafary F. Analysis and prioritization the effective factors on increasing farmers resilience under climate change and drought, Agricultural research, 2020.

https://doi.org/10.1007/s40003-020-00516-w

[18] Javadinejad S, Dara R and Jafary F. Climate Change Scenarios and Effects on Snow-Melt Runoff. Civil Engineering Journal, 2020, 6(9): 1715-1725 https://doi.org/10.28991/cej-2020-03091577

[19] Javadinejad S, Dara R, Hamed MH, et al. Analysis of Gray Water Recycling by Reuse of Industrial Waste Water for Agricultural and Irrigation Purposes, 2020. https://doi.org/10.30564/jgr.v3i2.2056

[20] Javadinejad S, Dara R and Jafary F. Impacts of Extreme Events on Water Availability. Annals of Geographical Studies, 2019, 2(3): 16-24. 
[21] Javadinejad S and Jafary RDF. Gray Water Measurement and Feasibility of Retrieval Using Innova-tive Technology and Application in Water Resources Management in Isfahan-Iran, 2020. https://doi.org/10.30564/jgr.v3i2.1997

[22] Javadinejad S, Dara R and Jafary F. Taking Urgent Actions to Combat Climate Change Impacts. Annals of Geographical Studies, 2019, 2(4): 1-13.

[23] Javadinejad S, Eslamian S and Ostad-Ali-Askari K. Investigation of monthly and seasonal changes of methane gas with respect to climate change using satellite data. Applied Water Science, 2019, 9(8): 180. https://doi.org/10.1007/s13201-019-1067-9

[24] Javadinejad S, Ostad-Ali-Askari K and Eslamian S. Application of Multi-Index Decision Analysis to Management Scenarios Considering Climate Change Prediction in the Zayandeh Rud River Basin. Water Conservation Science and Engineering, 2019, 4(1): 53-70 https://doi.org/10.1007/s41101-019-00068-3

[25] Javadinejad S, Eslamian S, Ostad-Ali-Askari K, et al. Embankments. In: Bobrowsky P., Marker B. (eds) Encyclopedia of Engineering Geology. Encyclopedia of Earth Sciences Series. Springer, Cham, 2018. https://doi.org/10.1007/978-3-319-12127-7_105-1

[26] Javadinejad S, Ostad-Ali-Askari K and Jafary F. Using simulation model to determine the regulation and to optimize the quantity of chlorine injection in water distribution networks. Modeling Earth Systems and Environment, 2019, 5(3): 1015-1023. https://doi.org/10.1007/s40808-019-00587-x

[27] Javadinejad S, Dara R and Jafary F. Modelling groundwater level fluctuation in an Indian coastal aquifer. Water SA, 2020, 46(4): 665-671.

[28] Javadinejad S, Dara R and Jafary F. Investigation of the effect of climate change on heat waves. Resources Environment and Information Engineering, 2020, 2(1): 54-60. https://doi.org/10.25082/REIE.2020.01.001

[29] Jiménez L, Rühland KM, Jeziorski A, et al. Climate change and Saharan dust drive recent cladoceran and primary pro- duction changes in remote alpine lakes of Sierra Nevada, Spain. Global change biology, 2018, 24(1): e139-e158. https://doi.org/10.1111/gcb.13878

[30] Javadinejad S, Dara R and Jafary F. Analysis and prioritization the effective factors on increasing farmers resilience under climate change and drought. Agricultural research, 2020: 1-17. https://doi.org/10.1007/s40003-020-00516-w

[31] Javadinejad S, Dara R and Jafary F. Modelling groundwater level fluctuation in an Indian coastal aquifer. Water SA, 2020, 46(4): 665-671. https://doi.org/10.17159/wsa/2020.v46.i4.9081

[32] Krumbein WC. Size frequency distributions of sediments. Journal of Sedimentary Petrology, 1934, 4: 65-77. https://doi.org/10.1306/D4268EB9-2B26-11D7-8648000 $102 \mathrm{C} 1865 \mathrm{D}$

[33] Folk RL and Ward WC. Brazos River bar: a study in the significance of grain size parameters. Journal of Sedimentary Petrology, 1957, 27: 3-26,. https://doi.org/10.1306/74D70646-2B21-11D7-864800010 2C1865D

[34] Javadinejad S. Vulnerability of water resources to climate change and human impact: scenario analysis of the Zayandeh Rud river basin in Iran (Doctoral dissertation, University of Birmingham), 2016.

[35] Javadinejad S, Eslamian S, Ostad-Ali-Askari K, et al. Relationship Between Climate Change, Natural Disaster, and Resilience in Rural and Urban Societies, 2019. https://doi.org/10.1007/978-3-319-93336-8_189

[36] Javadinejad S, Dara R and Jafary F. Health impacts of extreme events. Safety in Extreme Environments, 2020, 1: 111 . https://doi.org/10.1007/s42797-020-00016-8

[37] Javadinejad S, Ostad-Ali-Askari K, Singh VP, et al. Reliable, Resilient, and Sustainable Water Management in Different Water Use Sectors. Water Conservation Science and Engineering, 2019, 4(2-3): 133-148. https://doi.org/10.1007/s41101-019-00073-6 